\title{
2703. A novel high-strength large vibrating screen with duplex statically indeterminate mesh beam structure
}

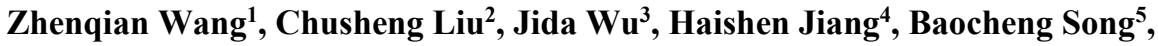 \\ Yuemin Zhao ${ }^{6}$ \\ 1,2,3,5 School of Mechatronic Engineering, China University of Mining and Technology, \\ Xuzhou, 221116, China \\ ${ }^{4,}{ }^{6} \mathrm{School}$ of Chemical Engineering and Technology, China University of Mining and Technology, \\ Xuzhou, 221116, China \\ ${ }^{2}$ Corresponding author \\ E-mail: ${ }^{1}$ wangzhenqian1988@126.com, ${ }^{2}$ liuchusheng@126.com, ${ }^{3}$ wujida09@163.com, \\ 4haishen_jiang2015@163.com,5flyingsbc@126.com,6ymzhao_paper@126.com
}

Received 9 March 2017; received in revised form 28 August 2017; accepted 20 September 2017 DOI https://doi.org/10.21595/jve.2017.18319

Check for updates

\begin{abstract}
Screening is an indispensable unit process for separation of materials. Large vibrating screen is extensively used in coal processing because of its large production capacity. In this study, a novel large vibrating screen with duplex statically indeterminate mesh beam structure (VSDSIMBS) was presented. The dynamic model of VSDSIMBS was proposed, and characteristic parameters were obtained by theoretical calculations. In order to obtain more reliable and believable research results, model of a traditional vibrating screen (TVS) with the same mass was also established for comparisons with VSDSIMBS. The finite element (FE) method was applied to study the performance of VSDSIMBS and FE analysis of VSDSIMBS and TVS was completed by using characteristic parameters. Modal analysis results indicated that VSDSIMBS could avoid the resonance and run more smoothly than TVS. Furthermore, harmonic response analysis results showed that VSDSIMBS could improve the entire stress distribution, reduce high stress areas, and increase the strength of vibrating screen. With DSIMBS, the maximum stress of vibrating screen decreased from 130.53 to $64.54 \mathrm{MPa}$. The full-scale experimental tests were performed to validate the credibility and accuracy of FE analysis results. The stress and displacements of VSDSIMBS were measured under working conditions. The test results obtained are in good agreement with simulation results, and accord with conclusions made from $\mathrm{FE}$ analysis.
\end{abstract}

Keywords: large vibrating screen, duplex statically indeterminate mesh beam structure, dynamic theoretical model, finite element method, high strength.

\section{Introduction}

Screening is an indispensable unit process for separation of materials in various industrial processes [1-2]. It is the oldest yet most important unit operation for coal processing. Vibrating screen is the key screening equipment in coal preparation and utilization, and widely used in the classification, dewatering, medium draining, and desliming of coal [3-5]. Attributed to its high capacity, large vibrating screen can simplify the coal preparation process, and reduce the initial cost [6-7]. With the increasing number of large-scale coal mines and coal preparation plants, the demand for large scale vibrating screen is becoming huge and progressively urgent [8-9].

With the increase in the screening area and capacity, the participating mass of a large vibrating screen is becoming huge. Thus, the vibrating screen has to bear the alternating heavy loading at high vibrating frequency [10]. This can lead to fractures of beams and cracking of side plates. Furthermore, a low reliability of screen structure, a low screening efficiency, high energy consumption, and a short product life can result [11]. Consequently, it cannot meet the production requirement of a large coal preparation plant. Therefore, a large-scale vibrating screen with high strength and rigidity is urgently needed.

Till date, extensive research efforts have been devoted to the study of large vibrating screens. Baragetti and Villa presented an innovative design strategy for the optimization of the dynamic 
performances and the structural loads of heavy loaded vibrating screens [12], and Baragetti proposed a new design solution for heavy loaded vibrating screens which allowed the enhancement of structural resistance and the dynamic performances of a vibrating screen for inert materials [13]. Jiang et al. proposed a novel large vibrating screen driven externally by an unbalanced two-axle excitation with a large span, and experimentally proved the excellent performance for coal screening [14-15]. Zhang et al. predicted the physical characteristics of a large vibrating screen from its scale-down model, and provided an effective method for structural optimization and substructure coupling analysis of the large vibrating screen [16]. Peng et al. improved the design of beam structures in large vibrating screen by considering bending and random vibration [17], and proposed a novel and feasible twice-suspended-mass method to deal with the seldom-studied issue of fault diagnosis for damping springs of large vibrating screen [18]. Cleary et al. used the discrete element method (DEM) to simulate a full industrial scale double deck banana screen for a range of accelerations [19-20]. Fernandez et al. introduced the use of smoothed particle hydrodynamics (SPH) to model the flow of slurry (water and fine material) through a double deck banana screen [21]. Zhou calculated and analyzed natural modes and distribution of dynamic stress of lateral plates [22]. Du et al. established five-freedom dynamic model and stability equations of the variable linear vibration screen based on power balance method [23]. Zhang and Wang built the dynamic model of polyurethane screen deck in sieving [24], and Zhang and Xu used the critical plane method for calculating the fatigue lives of the large linear vibrating screen [25].

However, most of these large vibrating screens always suffer from the strong external harmonic exciting force and the impact from the minerals, which easily lead to the fracture of the beam and the crack of the side plate. This has a negative effect on the reliability of the equipment itself and the industrial production. Therefore, considering the essential high reliability of the equipment, a novel large vibrating screen with duplex statically indeterminate mesh beam structure (VSDSIMBS) was put forward and patented [26]. This structure breaks through the limitation of traditional theory. The theory of statically indeterminate structure was applied to design large vibrating screen, and the DSIMBS was invented. This work is the intensive study on the basis of original work by Zhao et al. $[10,27]$. In this study, the structure of DSIMBS was redesigned to improve the bearing capacity and the structural strength. Theoretical analysis, FE analysis, and experimental validation were conducted to research the dynamic characteristics and structural strength of VSDSIMBS. Moreover, in order to obtain more reliable and believable research results, model of a traditional vibrating screen (TVS) with the same mass was also established for comparisons with VSDSIMBS.

\section{Comparison of structure between VSDSIMBS and TVS}

TVS is made up of screen body, screen surface, springs, and excitation system as shown in Fig. 1(a). The screen body includes side plates, bearing beams, spring supports, and stiffeners. The excitation system consists of two box vibrators connected with universal couplings. Box vibrators are fixed on exciting beam with high-strength bolts. With the rotation of the eccentric blocks within box vibrators, the screen body vibrates. Therefore, the connections between exciting beam and box vibrators bear alternating force. It has a high requirement on bearing alternating force and resisting deformation for connections.

Fig. 1(b) exhibits the structure of VSDSIMBS. Major components consist of screen body, screen surface, springs, and excitation system. The excitation system of VSDSIMBS is the DSIMBS, made up of four statically indeterminate plates, 16 mesh beams, and eight eccentric blocks as shown in Fig. 2. The length of beam significantly influences the deformation. Deformation increases with the increase in the length of the beam. Thus, the long beam was separated into multiple sections under permitting conditions, to considerably reduce the length of beam. By replacing box vibrators with eccentric blocks, the excitation system leads to the uniform distribution of the exciting force on DSIMBS, and reduces the deformation. 


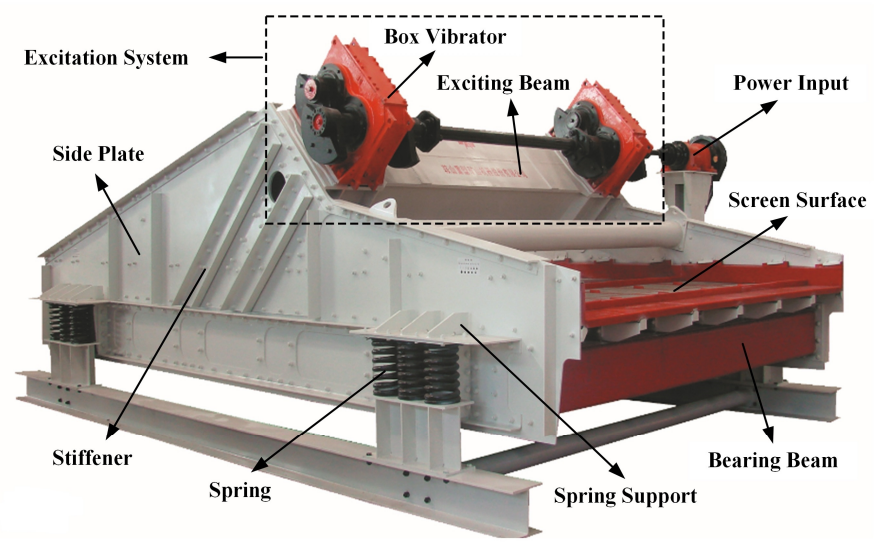

a)

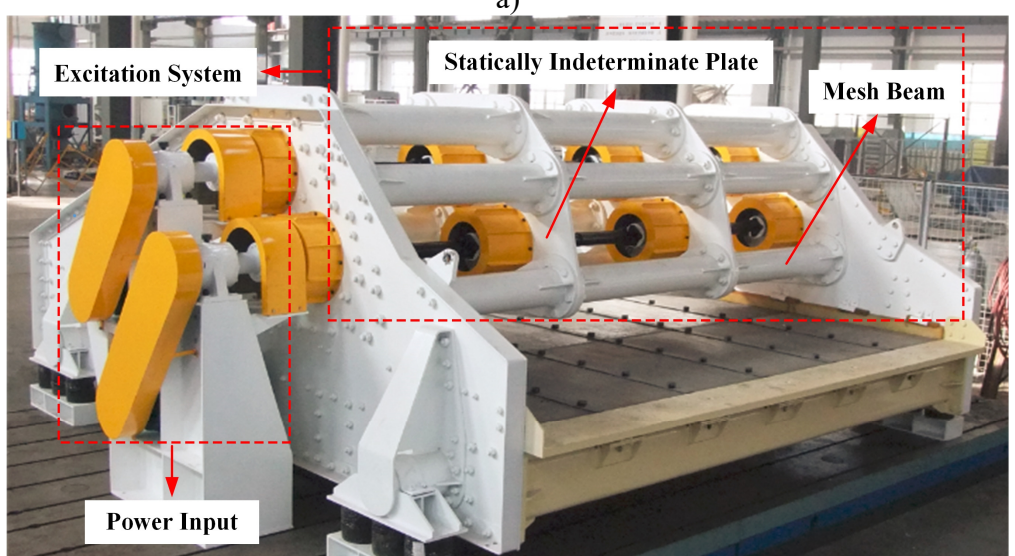

b)

Fig. 1. Structures of TVS and VSDSIMBS

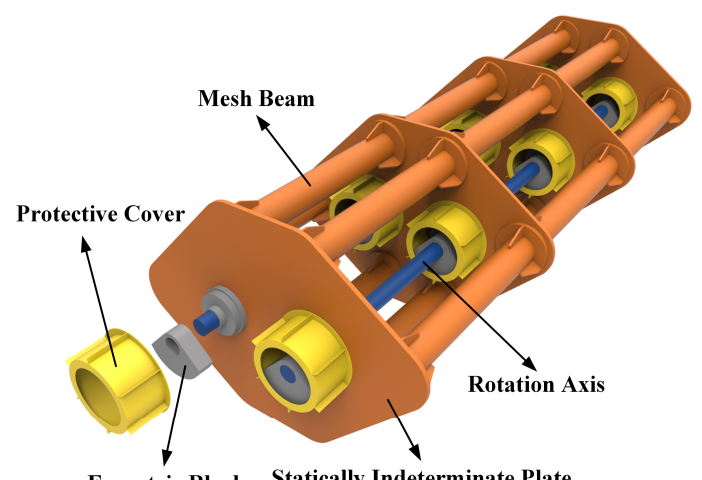

Eccentric Block Statically Indeterminate Plate

Fig. 2. Structure of DSIMBS

Multiple tubular beams with small diameter constitute the main load-bearing structure. Between these beams, statically indeterminate plates are applied to support each other. The beams and plates constitute DSIMBS. Redundant constraints in the interior of DSIMBS can change the stress distribution, decrease the peak stress, reduce the structural deformation, and improve the strength and rigidity of vibrating screen.

VSDSIMBS has been successfully applied and promoted in industrial field. C2WS4050, the prototype of VSDSIMBS, has been applied at Baodian coal preparation plant, Yankuang Group, 
Shandong, China in 2014. This vibrating screen is used to dewater and drain medium for coal gangue in heavy medium separation. The medium is recycled, and the water content of gangue decreases, and the corresponding process is shown in Fig. 3. C2WS4050 would be the object to research characteristics of VSDSIMBS in this study, and its structure is shown in Fig. 4.

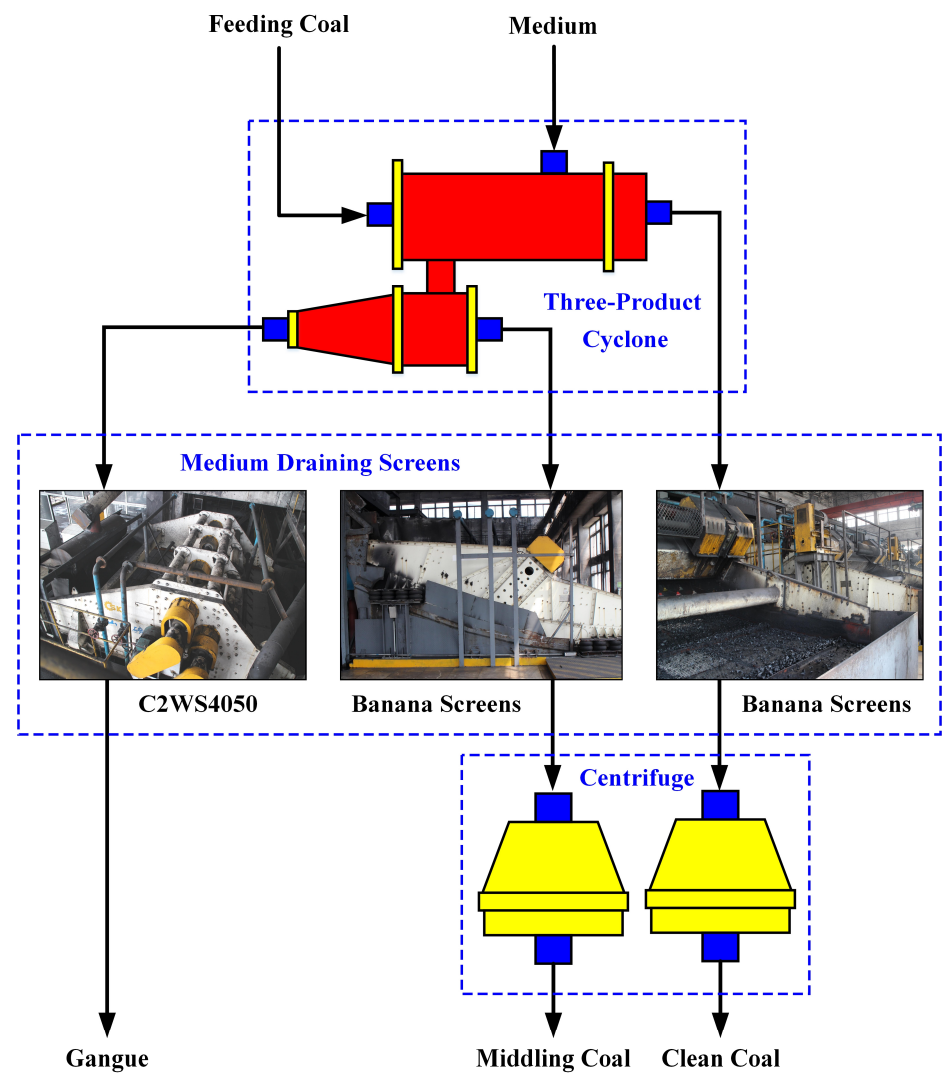

Fig. 3. Process chart of coal preparation plant

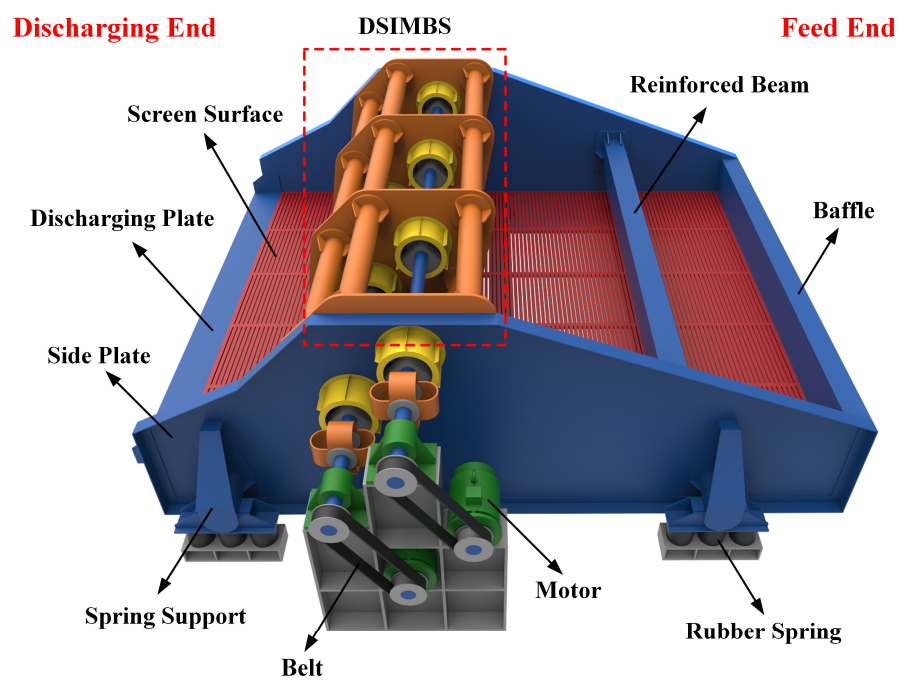

Fig. 4. Structure of C2WS4050 


\section{Dynamic model calculation of VSDSIMBS}

Prior to the FE analysis, the dynamic theoretical calculation was necessary to obtain relevant setting parameters, such as stiffness coefficient and exciting force. The natural frequency and displacement amplitude in horizontal and vertical directions of the vibrating screen could also be obtained by dynamic theory analysis. These parameters reflect the natural characteristics of the vibrating screen, and provide an important standard to evaluate the design rationality of the vibrating screen. VSDSIMBS is a type of dual-motors driving linear screen. The direction of the exciting force passes through the centroid of screen body. Ignoring the error caused by manufacturing, two degrees of freedom (2-DOF) dynamic model of C2WS4050 was built as shown in Fig. 5.

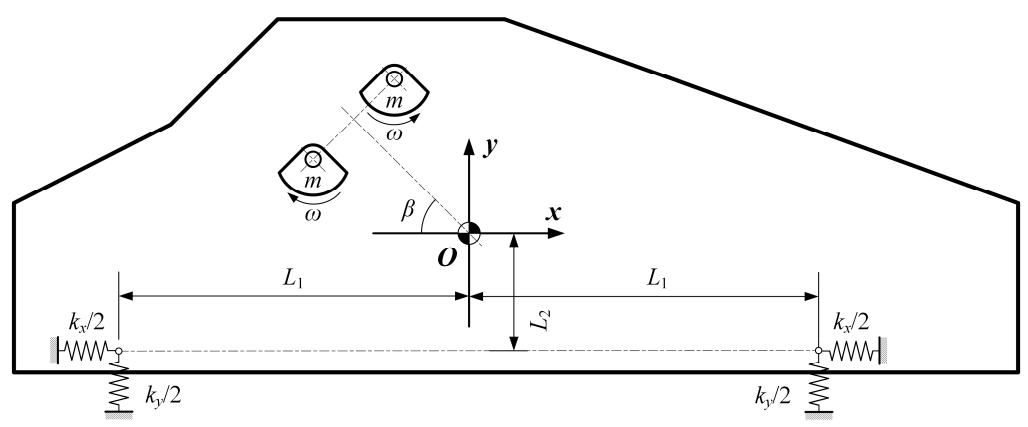

Fig. 5. Dynamic model of VSDSIMBS

\subsection{Calculation of stiffness}

12 rubber springs are used in C2WS4050. Compared to metal spring, rubber spring causes less noise, smaller amplitude when passing through resonance region, and it is beneficial to design by changing shape and stiffness according to requirements. The shore hardness $(H S)$ of rubber spring in use was measured by shore durometer. Shear modulus $(G)$ and tension and compression modulus $(E)$ can be obtained by using Eqs. (1-3):

$G=0.117 e^{0.03 H S}$,

$E=i G$,

$i=3.6\left[1+1.65\left(\frac{D-d}{4 h}\right)^{2}\right]$.

Shear stiffness $\left(k_{s}\right)$ and tension and compression stiffness $\left(k_{t}\right)$ of a single rubber spring can be calculated through Eq. (4). Total stiffness of all rubber springs in horizontal and vertical directions $\left(k_{x}, k_{y}\right)$ can be obtained by using Eq. (5):

$\left\{\begin{array}{l}k_{s}=G \frac{\pi\left(D^{2}-d^{2}\right)}{4 h}, \\ k_{t}=E \frac{\pi\left(D^{2}-d^{2}\right)}{4 h},\end{array}\right.$
$\left\{\begin{array}{l}k_{x}=12 k_{s}, \\ k_{y}=12 k_{t} .\end{array}\right.$

\subsection{Calculation of characteristic parameters}

The rotational speed of eccentric block $(n)$ was measured during field test and the angular velocity of eccentric block $(\omega)$ can be obtained through Eq. (6): 
$\omega=\frac{2 \pi n}{60}$.

When the eccentric blocks are rotating, the exciting force $(F)$ is directional harmonic force. The value of exciting force can be calculated by using Eq. (7). The exciting force in horizontal and vertical directions $\left(F_{x}, F_{y}\right)$ can be obtained through Eq. (8):

$F=2 m e \omega^{2} \sin \omega t$,

$\left\{F_{x}=2 m e \omega^{2} \sin \omega t \cos \beta\right.$,

$\left\{F_{y}=2 m e \omega^{2} \sin \omega t \sin \beta\right.$.

The differential equation of the vibration system is established as follows:

$\left\{\begin{array}{l}M \ddot{x}+c_{x} \dot{x}+k_{x} x=2 m e \omega^{2} \sin \omega t \cos \beta, \\ M \ddot{y}+c_{y} \dot{y}+k_{y} y=2 m e \omega^{2} \sin \omega t \sin \beta .\end{array}\right.$

Assuming that the displacement in horizontal and vertical directions $(x, y)$ has the following forms:

$\left\{\begin{array}{l}x=A_{x} \sin \left(\omega t-\alpha_{x}\right) \\ y=A_{y} \sin \left(\omega t-\alpha_{y}\right)\end{array}\right.$

Thus, the velocity and acceleration can be calculated through Eq. (11):

$\left\{\begin{array}{l}\dot{x}=A_{x} \omega \cos \left(\omega t-\alpha_{x}\right), \\ \ddot{x}=-A_{x} \omega^{2} \sin \left(\omega t-\alpha_{x}\right), \\ \dot{y}=A_{y} \omega \cos \left(\omega t-\alpha_{y}\right), \\ \ddot{y}=-A_{y} \omega^{2} \sin \left(\omega t-\alpha_{y}\right) .\end{array}\right.$

Substituting Eqs. (10-11) into Eq. (9), the displacement amplitude $\left(A_{x}, A_{y}\right)$ and phase angle $\left(\alpha_{x}, \alpha_{y}\right)$ can be obtained as follows:

$$
\left\{\begin{aligned}
A_{x} & =\frac{2 m e \omega^{2} \cos \beta}{\sqrt{\left(k_{x}-M \omega^{2}\right)^{2}+\left(c_{x} \omega\right)^{2}}} \\
A_{y} & =\frac{2 m e \omega^{2} \sin \beta}{\sqrt{\left(k_{y}-M \omega^{2}\right)^{2}+\left(c_{y} \omega\right)^{2}}} \\
\alpha_{x} & =\arctan \frac{c_{x} \omega}{k_{x}-M \omega^{2}} \\
\alpha_{y} & =\arctan \frac{c_{y} \omega}{k_{y}-M \omega^{2}}
\end{aligned}\right.
$$

The stiffness in horizontal direction is not equal to that in vertical direction; therefore, the vibration direction of the vibrating screen is different from that of the exciting force. The displacement amplitude in vibrating direction $(A)$ and the vibrating direction angle $\left(\beta_{0}\right)$ can be obtained through Eqs. (13-14):

$A=\sqrt{A_{x}^{2}+A_{y}^{2}}=2 m e \omega^{2} \sqrt{\frac{\cos ^{2} \beta}{\left(k_{x}-M \omega^{2}\right)^{2}+\left(c_{x} \omega\right)^{2}}+\frac{\sin ^{2} \beta}{\left(k_{y}-M \omega^{2}\right)^{2}+\left(c_{y} \omega\right)^{2}}}$, 
$\tan \beta_{0}=\frac{A_{y}}{A_{x}}=\sqrt{\frac{\left[k_{x}-M \omega^{2}\right]^{2}+\left(c_{x} \omega\right)^{2}}{\left[k_{y}-M \omega^{2}\right]^{2}+\left(c_{y} \omega\right)^{2}}} \tan \beta$.

The damping coefficient of rubber spring has little influence on the vibration system, thus it can be ignored in order to simplify the calculations. Eqs. (12-14) can be simplified to Eqs. (15-17), respectively:

$$
\begin{aligned}
& \left\{\begin{array}{l}
A_{x}=\frac{2 m e \omega^{2} \cos \beta}{\left|k_{x}-M \omega^{2}\right|}, \\
A_{y}=\frac{2 m e \omega^{2} \sin \beta}{\left|k_{y}-M \omega^{2}\right|},
\end{array}\right. \\
& A=2 m e \omega^{2} \sqrt{\frac{\cos ^{2} \beta}{\left(k_{x}-M \omega^{2}\right)^{2}}+\frac{\sin ^{2} \beta}{\left(k_{y}-M \omega^{2}\right)^{2}},} \\
& \tan \beta_{0}=\frac{A_{y}}{A_{x}}=\frac{\left|k_{x}-M \omega^{2}\right|}{\left|k_{y}-M \omega^{2}\right|} \tan \beta .
\end{aligned}
$$

In Eq. (15), when denominator is 0 , the first two natural frequencies of the vibration system can be calculated through Eq. (18):

$$
\left\{\begin{array}{l}
f_{x}=2 \pi \sqrt{\frac{k_{x}}{M}}, \\
f_{y}=2 \pi \sqrt{\frac{k_{y}}{M}} .
\end{array}\right.
$$

Through the calculation of the dynamic model, the dynamic characteristic parameters of VSDSIMBS can be obtained. All parameters used, and calculation results are listed in Table 1.

\section{Comparison between VSDSIMBS and TVS by FE method}

Further, in order to research the performance of VSDSIMBS more accurately, the FE method was applied to dynamic analysis on VSDSIMBS. A TVS with exciting beam was compared to VSDSIMBS with the objective of obtaining more intuitive and reliable analysis results.

An exciting beam was designed with the same mass as DSIMBS by using the traditional design method. Other components of vibrating screen, the value of exciting force and spring stiffness remained the same as VSDSIMBS. Box vibrator was selected to ensure that the exciting force remained unchanged. For the simplicity and accuracy, parts with little effect on strength were ignored, and mass points in FE software were used to replace vibrators and eccentric blocks. The FE models were built by using FE software as shown in Fig. 6 . The setting of exciting force and rubber spring was shown in this figure. The model of VSDSIMBS had 1071965 nodes and 222958 elements, and that of TVB had 811861 nodes and 159212 elements. Modal analysis and harmonic response analysis were performed to evaluate and compare the performance of the two types of vibrating screens as presented in Fig. 7.

\subsection{Modal analysis of VSDSIMBS and TVS}

The natural frequencies and mode shapes can be obtained through modal analysis. By comparing natural frequency with working frequency, it can be conjectured whether resonance 
occurs in working state. By observing mode shape, the deformation of screen body on natural frequency would be forecasted. Therefore, by utilizing FE software, the first 12 natural frequencies and mode shapes of VSDSIMBS and TVS were obtained, and the corresponding results are listed in Table 2.

Table 1. Parameters and calculation results

\begin{tabular}{|c|c|}
\hline Parameter & Value \\
\hline Shear modulus of rubber spring, $G(\mathrm{MPa})$ & 0.61 \\
\hline Tension and compression modulus of rubber spring, $E(\mathrm{MPa})$ & 2.31 \\
\hline Shore hardness of rubber spring, $H S$ & 55 \\
\hline Shape coefficient of ring rubber spring, $i$ & 3.79 \\
\hline Outer diameter of rubber spring, $D(\mathrm{~mm})$ & 180 \\
\hline Inner diameter of rubber spring, $d(\mathrm{~mm})$ & 50 \\
\hline Height of rubber spring, $h(\mathrm{~mm})$ & 180 \\
\hline Shear stiffness of rubber spring, $k_{s}(\mathrm{~N} / \mathrm{mm})$ & 79.48 \\
\hline Tension and compression stiffness of rubber spring, $k_{t}(\mathrm{~N} / \mathrm{mm})$ & 301.52 \\
\hline Total stiffness in horizontal direction, $k_{x}(\mathrm{~N} / \mathrm{mm})$ & 953.77 \\
\hline Total stiffness in vertical direction, $k_{y}(\mathrm{~N} / \mathrm{mm})$ & 3618.25 \\
\hline Total mass of screen body, $M(\mathrm{~kg})$ & 9105.30 \\
\hline Mass of eccentric block in single axis, $m(\mathrm{~kg})$ & 296.72 \\
\hline Rotational speed of eccentric block, $n(\mathrm{r} / \mathrm{min})$ & 831 \\
\hline Angular velocity of eccentric block, $\omega(\mathrm{rad} / \mathrm{s})$ & 87.02 \\
\hline Eccentricity of eccentric block, $e(\mathrm{~mm})$ & 7.83 \\
\hline Exciting force, $F(\mathrm{~N})$ & 351882.66 \\
\hline Exciting force in horizontal direction, $F_{x}(\mathrm{~N})$ & 248818.61 \\
\hline Exciting force in vertical direction, $F_{y}(\mathrm{~N})$ & 248818.61 \\
\hline Angle between exciting force and horizontal plane, $\beta\left(^{\circ}\right)$ & 45 \\
\hline Horizontal distance between spring support and centroid, $L_{1}(\mathrm{~mm})$ & 1825 \\
\hline Vertical distance between spring support and centroid, $L_{2}(\mathrm{~mm})$ & 627.59 \\
\hline Damping coefficient in horizontal direction, $c_{x}(\mathrm{Ns} / \mathrm{mm})$ & 0 \\
\hline Damping coefficient in vertical direction, $c_{y}(\mathrm{Ns} / \mathrm{mm})$ & 0 \\
\hline Phase angle in in horizontal direction, $\alpha_{x}\left(^{\circ}\right)$ & 0 \\
\hline Phase angle in in vertical direction, $\alpha_{y}\left({ }^{\circ}\right)$ & 0 \\
\hline Displacement amplitude in horizontal direction, $A_{x}(\mathrm{~mm})$ & 3.66 \\
\hline Displacement amplitude in vertical direction, $A_{y}(\mathrm{~mm})$ & 3.81 \\
\hline Natural frequency in horizontal direction, $f_{x}(\mathrm{~Hz})$ & 1.63 \\
\hline Natural frequency in vertical direction, $f_{y}(\mathrm{~Hz})$ & 3.17 \\
\hline Displacement amplitude in vibrating direction, $A(\mathrm{~mm})$ & 5.28 \\
\hline Vibrating direction angle, $\beta_{0}\left({ }^{\circ}\right)$ & 46.14 \\
\hline
\end{tabular}

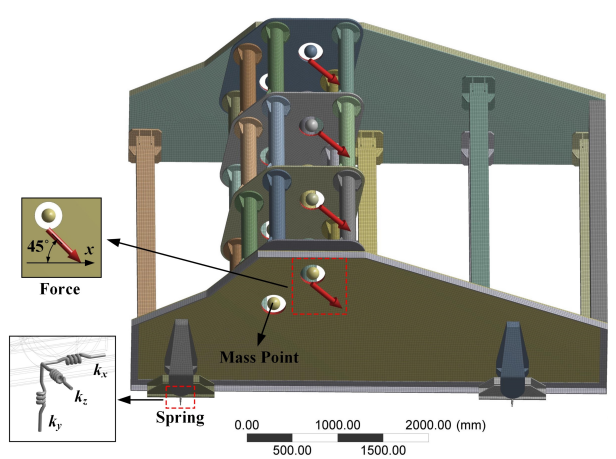

a)

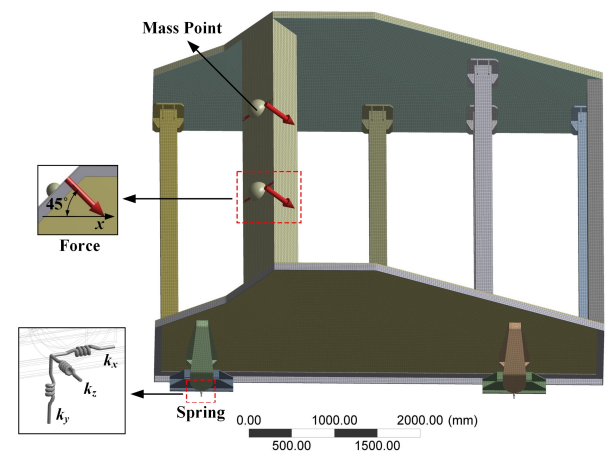

b)

Fig. 6. FE models of: a) VSDSIMBS, b) TVS 


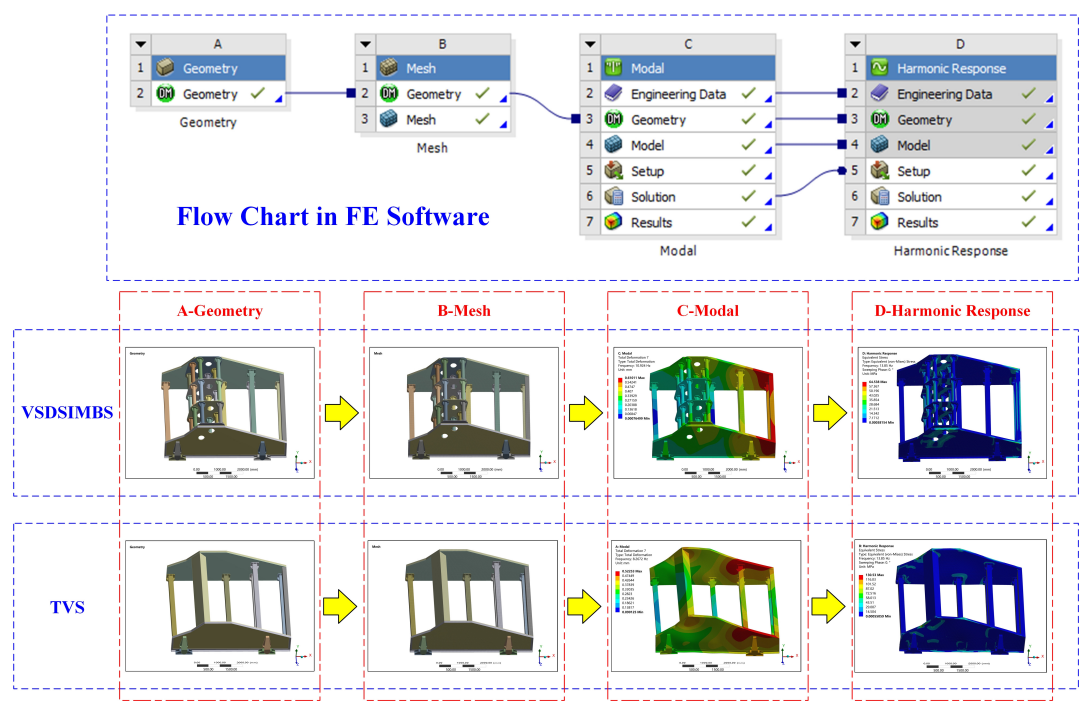

Fig. 7. Flow chart of FE analysis

Table 2. Natural frequencies and mode shapes of VSDSIMBS and TVS

\begin{tabular}{|c|c|c|c|c|}
\hline \multirow[b]{2}{*}{ Order } & \multicolumn{2}{|r|}{ VSDSIMBS } & \multicolumn{2}{|r|}{ TVS } \\
\hline & $\begin{array}{l}\text { Natural } \\
\text { frequency } \\
(\mathrm{Hz})\end{array}$ & Mode shape & $\begin{array}{l}\text { Natural } \\
\text { frequency } \\
(\mathrm{Hz})\end{array}$ & Mode shape \\
\hline 1 & 1.76 & Translation along $x$ axis & 1.74 & Translation along $Z$ axis \\
\hline 2 & 1.77 & Translation along $z$ axis & 1.76 & Translation along $x$ axis \\
\hline 3 & 2.52 & Rotation along $y$ axis & 2.57 & Rotation along $y$ axis \\
\hline 4 & 3.15 & Translation along $y$ axis & 3.14 & Translation along $y$ axis \\
\hline 5 & 3.97 & Rotation along $z$ axis & 3.80 & Rotation along $Z$ axis \\
\hline 6 & 4.41 & Rotation along $x$ axis & 4.74 & Rotation along $x$ axis \\
\hline 7 & 10.92 & $\begin{array}{l}\text { Reverse translation of discharging } \\
\text { plate and baffle along } z \text { axis }\end{array}$ & 8.27 & $\begin{array}{l}\text { Reverse translation of discharging } \\
\text { plate and baffle along } z \text { axis }\end{array}$ \\
\hline 8 & 16.33 & $\begin{array}{l}\text { Reverse rotation of side plate on } \\
\text { both sides along } z \text { axis }\end{array}$ & 14.11 & $\begin{array}{c}\text { Translation of discharging plate } \\
\text { along } z \text { axis }\end{array}$ \\
\hline 9 & 20.62 & $\begin{array}{c}\text { Translation of discharging plate } \\
\text { along } z \text { axis }\end{array}$ & 19.76 & $\begin{array}{l}\text { Reverse translation of discharging } \\
\text { plate, DSIMBS, and baffle along } z \\
\text { axis }\end{array}$ \\
\hline 10 & 24.28 & $\begin{array}{l}\text { Reverse translation of discharging } \\
\text { plate, DSIMBS, and baffle along } z \\
\text { axis }\end{array}$ & 20.35 & $\begin{array}{l}\text { Reverse rotation of side plate on } \\
\text { both sides along } z \text { axis }\end{array}$ \\
\hline 11 & 32.44 & $\begin{array}{l}\text { Reverse translation of side plate on } \\
\text { both sides along } z \text { axis }\end{array}$ & 26.18 & $\begin{array}{l}\text { Reverse translation of reinforced } \\
\text { beam and bearing beam along } z \\
\text { axis }\end{array}$ \\
\hline 12 & 35.86 & $\begin{array}{c}\text { Reverse translation of DSIMBS } \\
\text { and baffle along } z \text { axis }\end{array}$ & 32.04 & $\begin{array}{l}\text { Reverse translation of side plate on } \\
\text { both sides along } z \text { axis }\end{array}$ \\
\hline
\end{tabular}

The values listed in Table 2 indicate that the mode shapes of vibrating screens are mainly rigid motion and bending deformation of screen body. The first six natural frequencies correspond to the rigid motion of vibrating screens. Only the rubber springs were deformed. The values of natural frequencies were just depended on the mass of screen body and stiffness of spring. Therefore, the first six natural frequencies of VSDSIMBS were same as those of TVS. The last 6 natural frequencies were ascribed to the bending deformation of screen body. Clearly, the natural frequencies of VSDSIMBS are much larger and significantly different from the working 
frequency $(13.85 \mathrm{~Hz})$ than those of TVS. These results indicate that VSDSIMBS can avoid the resonance during working, reduce the stress of screen body, and improve the working life effectively.

\subsection{Harmonic response analysis of VSDSIMBS and TVS}

During the working process, the screen body of vibrating screen bears the alternating force produced by motors. This force would lead to large stress and deformation of key components, such as exciting beam and side plates, of the vibrating screen.

Steady-state response under harmonic load can be obtained by harmonic response analysis. The exciting force is harmonic force, thus the stress and displacement of vibrating screen at working frequency can be obtained by harmonic response analysis.

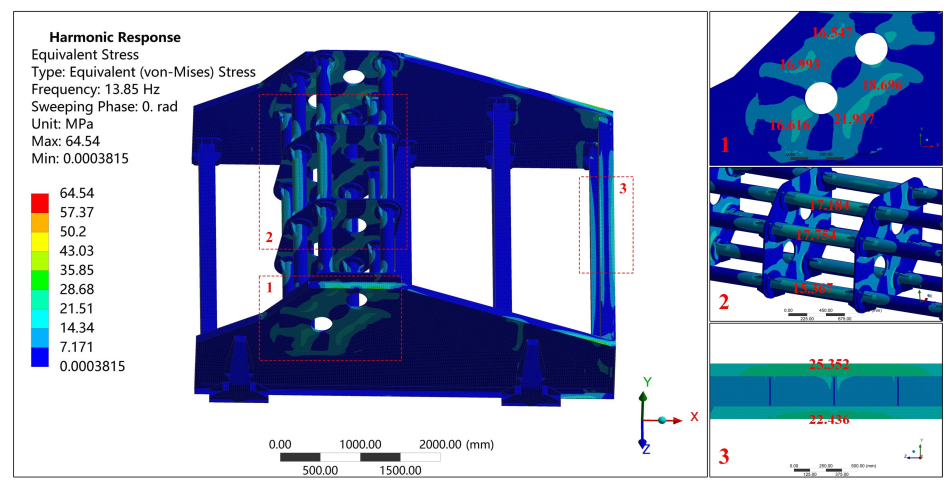

a)

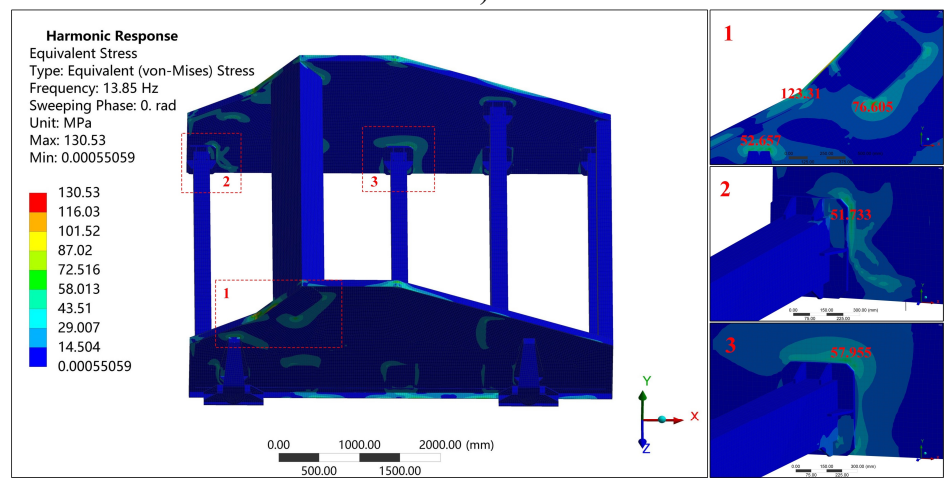

b)

Fig. 8. Stress nephograms of: a) VSDSIMBS, b) TVS

Fig. 8 shows the stress nephograms of VSDSIMBS and TVS at the working frequency (13.85 Hz). Fig. 8(a) clearly demonstrates that the high stress areas of VSDSIMBS are mainly distributed in DSIMBS; the stress in the middle of DSIMBS is larger than that on both sides; and the maximum stress is $64.54 \mathrm{MPa}$, which is far less than the yield strength of material used (235 MPa). Fig. 8(b) exhibits that the high stress areas of TVS are mainly distributed in side plates, in particular, in the junctions of side plates and beams; and the maximum stress is $130.53 \mathrm{MPa}$, significantly larger compared to that of DSIMBS.

In order to obtain more direct and obvious computed results, the display of stress nephograms was rebuilt by changing legends as shown in Fig. 9. Fig. 9(a) shows that the stress of VSDSIMBS is generally less than $20 \mathrm{MPa}$. However, Fig. 9(b) exhibits many areas in side plates of TVS, where stress is larger than $20 \mathrm{MPa}$, even $30 \mathrm{MPa}$. Therefore, this result indicates that the overall structural strength of VSDSIMBS is better than that of TVS. 


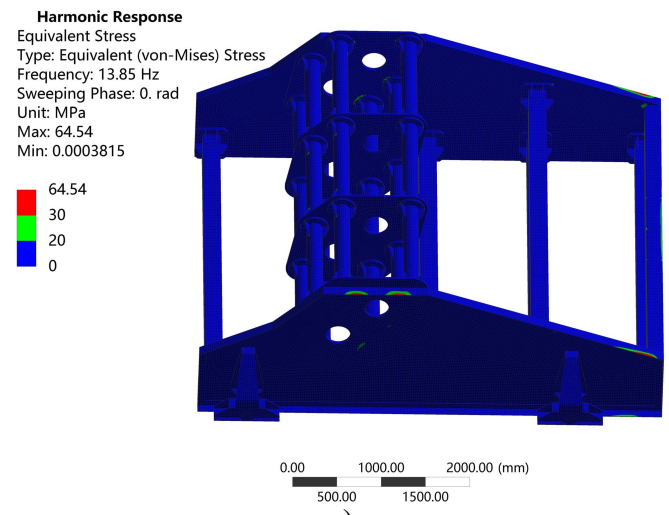

a)

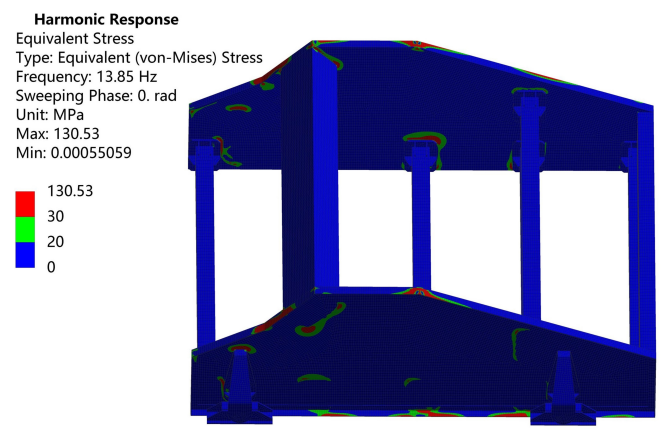

$\frac{0.00}{500.00} 1000.00 \quad 2000.00(\mathrm{~mm})$

b)

Fig. 9. Rebuilt stress nephograms of: a) VSDSIMBS, b) TVS

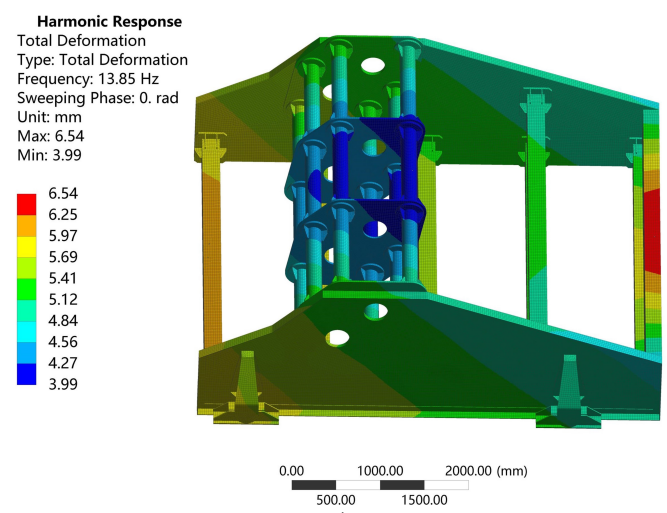

a)

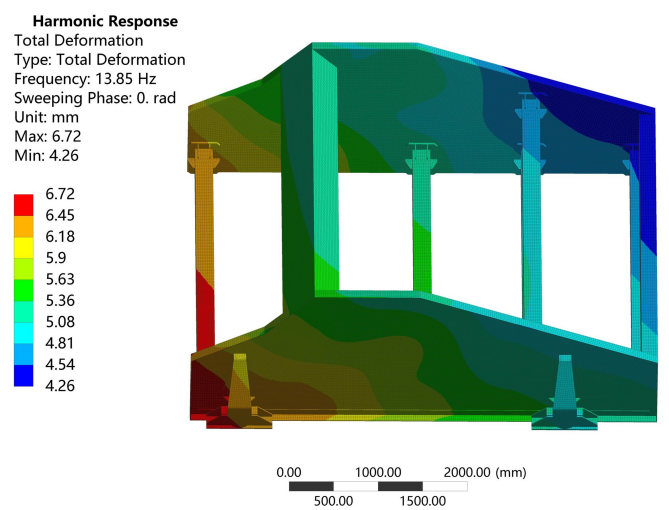

b)

Fig. 10. Displacement nephograms of: a) VSDSIMBS, b) TVS

Fig. 10 shows the displacement nephograms of VSDSIMBS and TVS at the working frequency $(13.85 \mathrm{~Hz})$. Fig. 10(a) exhibits the displacement nephogram of VSDSIMBS, demonstrating that the displacement of DSIMBS is less than those of feed end and discharging end; and the displacement of feed end is slightly larger than that of discharging end. Fig. 10(b) shows the displacement nephogram of TVS, revealing that the displacement of feed end is far less than that of discharging end. This indicates that TVS swings back and forth with high magnitude under working state. Thus, VSDSIMBS runs more smoothly than TVS.

The simulation results of FE analysis indicate that DSIMBS exhibits greater contacting areas with side plates than traditional exciting beam. This can effectively improve the entire stress and displacement distribution of vibrating screen, and make DSIMBS the main supporting part. Unlike VSDSIMBS, side plates of TVS mainly bear the loading. Compared to side plates, the DSIMBS is easier to be maintained and replaced. Moreover, DSIMBS can reduce the stress of vibrating screen under the same loading conditions, and increase the strength of vibrating screen. Thus, VSDSIMBS has many advantages over TVS.

\section{Full-scale experimental tests on VSDSIMBS and comparisons between simulation results and test results}

The simulation results indicated that the stress in the middle of DSIMBS was greater than that on both sides, and the displacement of DSIMBS was less than those of feed end and discharging end. In order to verify the credibility and accuracy of simulation results, the field test on VSDSIMBS was necessary. C2WS4050 at coal preparation plant was used as the test object. The 
stress of DSIMBS was obtained by resistance strain gauges, and 3-axis acceleration sensors were applied to measure the displacements of VSDSIMBS. Related experimental instruments were connected, and test signals were collected and processed [28-31]. The flow chart of field tests is shown in Fig. 11.

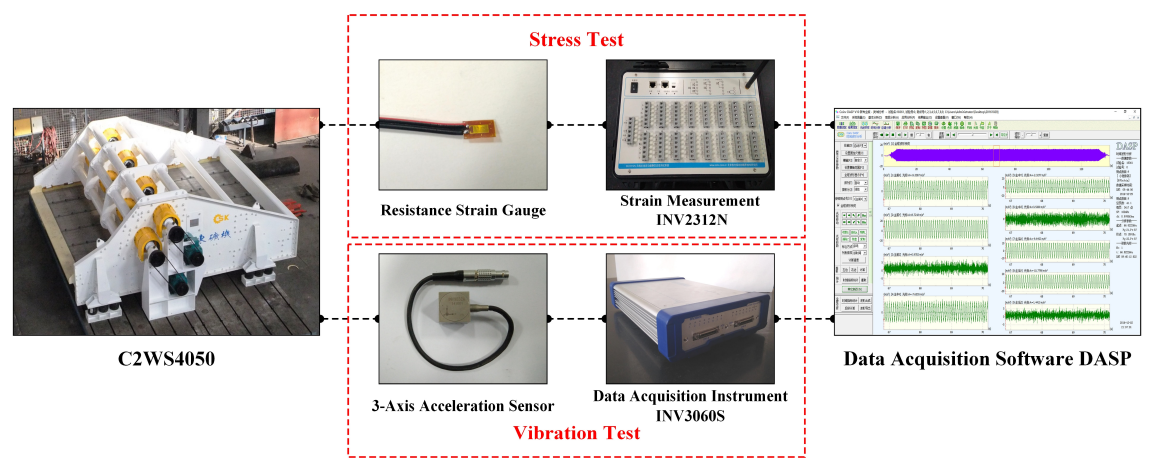

Fig. 11. Flow chart of field tests

18 resistance strain gauges were, respectively, arranged at 18 mesh beams of DSIMBS to obtain the stress of DSIMBS. Three 3-axis acceleration sensors (A1-A3) were placed at the middle of baffle (A1), DSIMBS (A2), and discharging plate (A3), to measure the displacement of feed end, DSIMBS, and discharging end, separately. The arrangement of gauges and sensors is shown in Fig. 12. Then the stress and displacements were obtained.

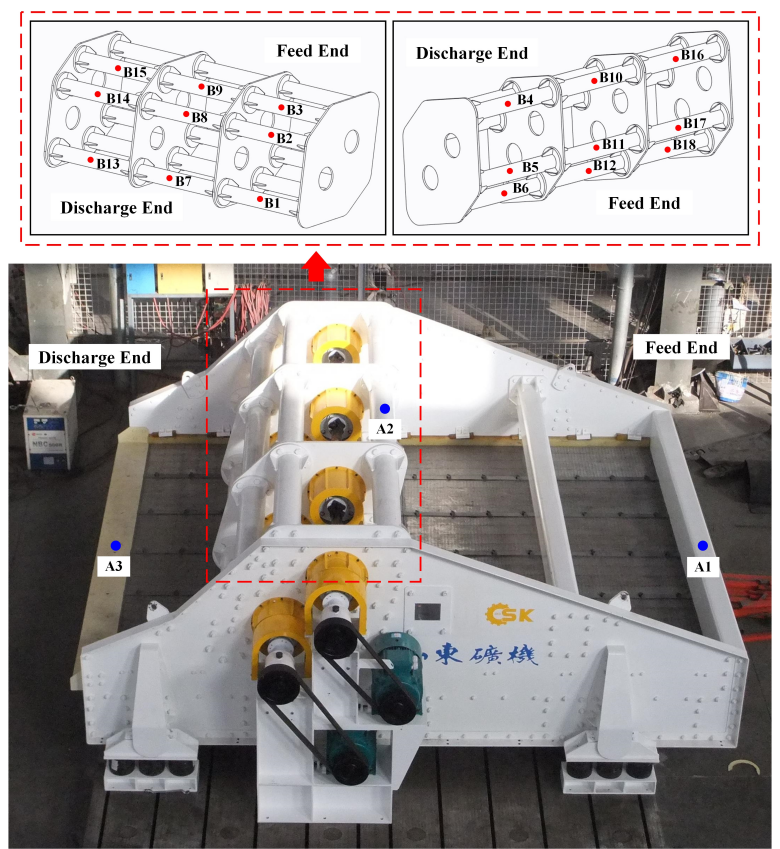

Fig. 12. Schematic illustration of gauges and sensors arrangement

Simulation results of same measuring points were obtained from FE analysis, and compared with test results listed in Tables 3-4 and shown in Fig. 13.

Table 3 and Fig. 13(a) show that the displacement of DSIMBS (A2) is less than that of feed end (A1) and discharging end (A3). Further, Table 4 and Fig. 13(b) exhibit that the stress in the middle of DSIMBS (B7-B12) is larger than that on both sides (B1-B6, B13-B18). 
Table 3. Comparison of displacement between test results and simulation results

\begin{tabular}{|c|c|c|c|}
\hline Measuring point & $\begin{array}{c}\text { Test result } \\
(\mathrm{mm})\end{array}$ & $\begin{array}{c}\text { Simulation result } \\
(\mathrm{mm})\end{array}$ & Relative error \\
\hline $\mathrm{A} 1$ & 6.39 & 6.51 & $1.88 \%$ \\
\hline $\mathrm{A} 2$ & 3.87 & 3.99 & $3.10 \%$ \\
\hline $\mathrm{A} 3$ & 6.05 & 6.17 & $1.98 \%$ \\
\hline
\end{tabular}

Table 4. Comparison of stress between test results and simulation results

\begin{tabular}{|c|c|c|c|}
\hline Measuring point & $\begin{array}{c}\text { Test result } \\
(\mathrm{MPa})\end{array}$ & $\begin{array}{c}\text { Simulation result } \\
(\mathrm{MPa})\end{array}$ & Relative error \\
\hline B1 & 2.00 & 2.08 & $3.85 \%$ \\
\hline B2 & 2.90 & 2.81 & $3.20 \%$ \\
\hline B3 & 4.80 & 4.67 & $2.84 \%$ \\
\hline B4 & 2.50 & 2.59 & $3.47 \%$ \\
\hline B5 & 5.10 & 4.85 & $5.15 \%$ \\
\hline B6 & 3.40 & 3.25 & $4.62 \%$ \\
\hline B7 & 14.20 & 15.23 & $6.76 \%$ \\
\hline B8 & 16.30 & 17.48 & $6.75 \%$ \\
\hline B9 & 18.80 & 17.69 & $6.27 \%$ \\
\hline B10 & 15.90 & 16.63 & $4.39 \%$ \\
\hline B11 & 16.80 & 17.24 & $2.55 \%$ \\
\hline B12 & 14.90 & 15.95 & $6.58 \%$ \\
\hline B13 & 4.50 & 4.26 & $5.63 \%$ \\
\hline B14 & 4.80 & 5.08 & $5.51 \%$ \\
\hline B15 & 5.80 & 6.04 & $3.97 \%$ \\
\hline B16 & 5.20 & 4.87 & $6.78 \%$ \\
\hline B18 & 5.10 & 5.34 & $4.49 \%$ \\
\hline & 3.60 & 3.42 & $5.26 \%$ \\
\hline
\end{tabular}

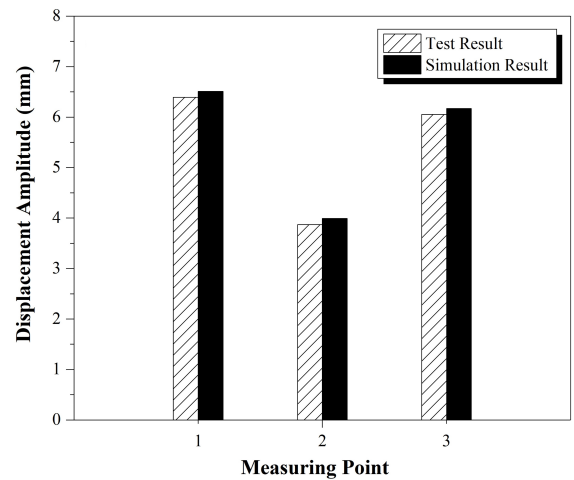

a)

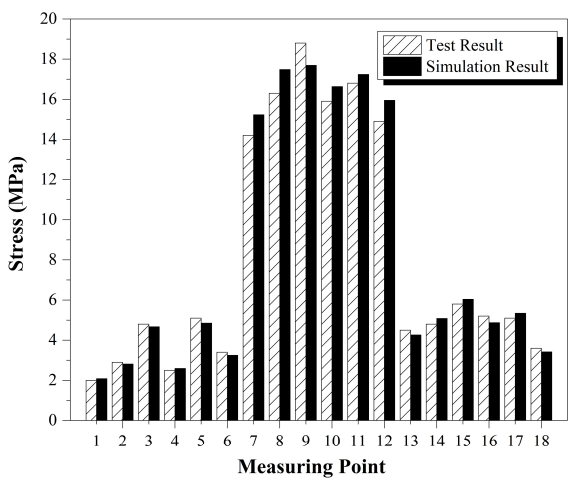

b)

Fig. 13. Comparisons of: a) displacement, b) stress between test results and simulation results

Considering the instrumental precision and field interference, the test results are within acceptable limits. The maximum relative error between simulation result and test result is $6.78 \%$. According to [13], the errors those are less than $7 \%$ can be considered as negligible. Ignoring tolerance errors, test results are in good agreement with simulation results, and can meet conclusions of FE analysis. This indicates that simulation results have high reliability and accuracy, and conclusions obtained by FE method are in well agreement with the actual working situation.

Liu conceived and designed the experiments. Wang, Wu, Jiang and Song performed the experiments. Wang analyzed the data and wrote the manuscript. Zhao helped perform the analysis with constructive discussions. 


\section{Conclusions}

A novel large vibrating screen with DSIMBS was proposed in this study. The dynamic model of VSDSIMBS was set up, and characteristic parameters were obtained by theoretical calculation. The FE analysis of VSDSIMBS and TVS was completed, and the full-scale experimental tests were also accomplished.

1) The natural frequencies of VSDSIMBS were much larger and significantly different from the working frequency than those of TVS. This indicated that VSDSIMBS could avoid the resonance and run more smoothly than TVS during working.

2) The stress of VSDSIMBS was generally less than $20 \mathrm{MPa}$, while that of parts of TVS was larger than $20 \mathrm{MPa}$, even $30 \mathrm{MPa}$. In vibrating screen with DSIMBS, the maximum stress reduced from 130.53 to $64.54 \mathrm{MPa}$, and the high stress areas decreased under the same conditions. The simulation results showed that VSDSIMBS could improve the entire stress distribution, and increase the strength of vibrating screen.

3) The stress and displacements of VSDSIMBS were measured on the field. The maximum relative error between simulation result and test result was $6.78 \%$, the test results were in good agreement with simulation results. This indicated that the conclusions obtained by FE method were in well agreement with the actual working situation.

4) This study proved that the DSIMBS had a great influence on performance of vibrating screen. DSIMBS would be conducive to increase the strength and improve the stress distribution of vibrating screen. VSDSIMBS provided a feasible and reliable scheme for large vibrating screen.

\section{Acknowledgements}

The research work is financially supported by the National Natural Science Foundation of China (Nos. U1508210, 51620105001, 51775544), Jiangsu Province Research Prospective Project (No. BY2015023-01).

\section{References}

[1] Dong K. J., Yu A. B., Brake I. DEM simulation of particle flow on a multi-deck banana screen. Minerals Engineering, Vol. 22, Issue 11, 2009, p. 910-920.

[2] Jahani M., Farzanegan A., Noaparast M. Investigation of screening performance of banana screens using LIGGGHTS DEM solver. Powder Technology, Vol. 283, 2015, p. 32-47.

[3] Makinde O. A., Mpofu K., Popoola A. P. I. Review of the status of reconfigurable manufacturing systems (RMS) application in South Africa mining machinery industries. Proceedings of the 47th Cirp Conference on Manufacturing Systems: Variety Management in Manufacturing, Vol. 17, 2014, p. 136-141.

[4] Song B. C., Liu C. S., Peng L. P., Li J. Dynamic analysis of new type elastic screen surface with multi degree of freedom and experimental validation. Journal of Central South University, Vol. 22, Issue 4, 2015, p. 1334-1341.

[5] Noble A., Luttrell G. H. A review of state-of-the-art processing operations in coal preparation. International Journal of Mining Science and Technology, Vol. 25, Issue 4, 2015, p. 511-521.

[6] Liu K. S. Some factors affecting sieving performance and efficiency. Powder Technology, Vol. 193, Issue 2, 2009, p. 208-213.

[7] Zhao L. L., Zhao Y. M., Sao C. Y., Hou Q. F., Yu A. B. Laboratory-scale validation of a DEM model of screening processes with circular vibration. Powder Technology, Vol. 303, 2016, p. 269-277.

[8] Wen B. Recent development of vibration utilization engineering. Frontiers of Mechanical Engineering in China, Vol. 3, Issue 1, 2008, p. 1-9.

[9] Zhao Y., Liu J., Wei X., Luo Z., Chen Q., Song S. New progress in the processing and efficient utilization of coal. Mining Science and Technology, Vol. 21, Issue 4, 2011, p. 547-552.

[10] Zhao Y. M., Liu C. S., He X. M., Zhang C. Y., Wang Y. B., Ren Z. T. Dynamic design theory and application of large vibrating screen. Procedia Earth and Planetary Science, Vol. 1, Issue 1, 2009, p. 776-784. 
[11] Steyn J. Fatigue failure of deck support beams on a vibrating screen. International Journal of Pressure Vessels and Piping, Vol. 21, Issue 4, 1995, p. 315-327.

[12] Baragetti S., Villa F. A dynamic optimization theoretical method for heavy loaded vibrating screens. Nonlinear Dynamics, Vol. 78, Issue 1, 2014, p. 609-627.

[13] Baragetti S. Innovative structural solution for heavy loaded vibrating screens. Minerals Engineering, Vol. 84, 2015, p. 15-26.

[14] Jiang H. S., Zhao Y. M., Duan C. L., Yang X. L., Liu C. S., Wu J. D., Qiao J. P., Diao H. R. Kinematics of variable-amplitude screen and analysis of particle behavior during the process of coal screening. Powder Technology, Vol. 306, 2017, p. 88-95.

[15] Jiang H. S., Zhao Y. M., Duan C. L., Zhang C. Y., Diao H. R., Wang Z. Q., Fan X. C. Properties of technological factors on screening performance of coal in an equal-thickness screen with variable amplitude. Fuel, Vol. 188, 2017, p. 511-521.

[16] Zhang Z. R., Wang Y. Y., Fan Z. M. Similarity analysis between scale model and prototype of large vibrating screen. Shock and Vibration, Vol. 2015, 2015, p. 1-7.

[17] Peng L. P., Liu C. S., Song B. C., Wu J. D., Wang S. Improvement for design of beam structures in large vibrating screen considering bending and random vibration. Journal of Central South University, Vol. 22, Issue 9, 2015, p. 3380-3388.

[18] Peng L. P., Liu C. S., Li J., Wang H. Static-deformation based fault diagnosis for damping spring of large vibrating screen. Journal of Central South University, Vol. 21, Issue 4, 2014, p. 1313-1321.

[19] Cleary P. W., Sinnott M. D., Morrison R. D. Separation performance of double deck banana screens - Part 1: Flow and separation for different accelerations. Minerals Engineering, Vol. 22, Issue 14, 2009, p. 1218-1229.

[20] Cleary P. W., Sinnott M. D., Morrison R. D. Separation performance of double deck banana screens - Part 2: Quantitative predictions. Minerals Engineering, Vol. 22, Issue 14, 2009, p. 1230-1244.

[21] Fernandez J. W., Cleary P. W., Sinnott M. D., Morrison R. D. Using SPH one-way coupled to DEM to model wet industrial banana screens. Minerals Engineering, Vol. 24, Issue 8, 2011, p. 741-753.

[22] Zhou N. Dynamic characteristics analysis and optimization for lateral plates of the vibration screen. Journal of Vibroengineering, Vol. 17, Issue 4, 2015, p. 1593-1604.

[23] Du C. L., Gao K. D., Li J. P., Jiang H. Dynamics behavior research on variable linear vibration screen with flexible screen face. Advances in Mechanical Engineering, Vol. 2014, 2014, p. 1-12.

[24] Zhang Z. R., Wang Y. Y. Deformation analysis of polyurethane screen deck in linear vibrating screen. Advanced Polymer Science and Engineering, Vol. 221, 2011, p. 240-246.

[25] Zhang Z. R., Xu J. Fatigue analysis of linear vibrating screen with different surface roughness. Advanced Polymer Processing III, Vol. 561, 2013, p. 564-567.

[26] Zhao Y. M., Zhang C. Y. Extra-Large Vibrating Screen with Duplex Statically Indeterminate Mesh Beam. United States Patent, US8074805 B2, 2007.

[27] Zhao Y. M., Liu C. S., Li F. M., Peng L. P., Song B. C., Dong H. L., Duan C. L. Dynamic analysis and optimization of a large-scale vibrating screen with high reliability. 27th International Mineral Processing Congress, 2014, p. 116-124.

[28] Du J., Xiao P., Wu J., Chen Q. Design of isotropic orthogonal transform algorithm-based multicarrier systems with blind channel estimation. IET Communications, Vol. 6, Issue 16, 2012, p. 2695-2704.

[29] Yang K., Yang N., Xing C. W., Wu J. S., Zhang Z. S. Space-time network coding with transmit antenna selection and maximal-ratio combining. IEEE Transactions on Wireless Communications, Vol. 14, Issue 4, 2015, p. 2106-2117.

[30] Han F. X., Zhao S. J., Zhang L., Wu J. S. Survey of strategies for switching off base stations in heterogeneous networks for greener 5G systems. IEEE Access, Vol. 4, 2016, p. 4959-4973.

[31] Serrano P., Costa Perez X., Wu J., Christensen K. Special issue: green communications. Computer Networks, Vol. 78, 2015, p. 1-3.

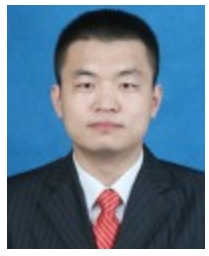

Zhenqian Wang received Master degree in School of Mechatronic Engineering from China University of Mining and Technology (CUMT), Xuzhou, China in 2013. Now he studies for a Ph.D. in CUMT. His current research is dynamics and DEM. 


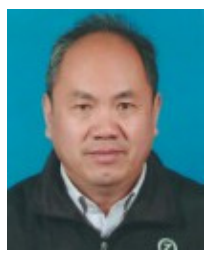

Chusheng Liu received Ph.D. degree in School of Chemical Engineering and Technology from China University of Mining and Technology (CUMT), Xuzhou, China in 1997. Now he works in CUMT as a Professor. His current research is dynamics, optimization and DEM.

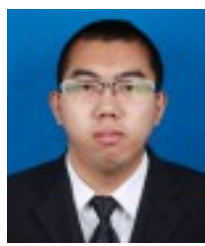

Jida Wu received Master degree in School of Mechatronic Engineering from China University of Mining and Technology (CUMT), Xuzhou, China in 2016. Now he studies for a Ph.D. in CUMT. His current research is dynamics and optimization.

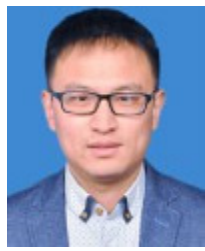

Haishen Jiang received Bachelor degree in School of Chemical Engineering and Technology from China University of Mining and Technology (CUMT), Xuzhou, China in 2012. Now he studies for a Ph.D. in CUMT. His current research is screening and separation.

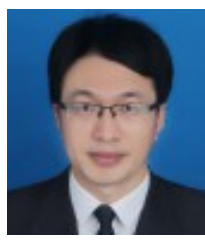

Baocheng Song received Master degree in School of Mechatronic Engineering from China University of Mining and Technology (CUMT), Xuzhou, China in 2013. Now he studies for a Ph.D. in CUMT. His current research is dynamics and DEM.

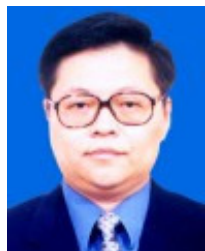

Yuemin Zhao received Ph.D. degree in School of Chemical Engineering and Technology from China University of Mining and Technology (CUMT), Xuzhou, China in 1991. Now he works in CUMT as vice-president. His current research is screening and separation. 